\title{
Soldadura laser de chapa fina de aço carbono e aço galvanizado
}

\author{
P. Peças ${ }^{(*)}$, H. Gouveia ${ }^{(*)}$ e L. Quintino ${ }^{(* *)}$
}

\begin{abstract}
Resumo: Este artigo descreve os resultados da investigação da soldadura laser de $\mathrm{CO}_{2}$ de chapa fina de aço carbono (simples e galvanizado), em diferentes combinações de espessura. A soldadura laser é um processo de elevado potencial no fabrico de tailored-blanks (sub-conjuntos para posterior enformação, constituídos por várias partes de diferentes materiais e espessuras) para a indústria automóvel.

São analisados os aspectos de optimização paramétrica, de qualidade metalúrgica da junta soldada e das deformações resultantes da soldadura. São descritos os mecanismos desenvolvidos de fixação das chapas e protecção gasosa, por forma a minimizar os defeitos típicos na soldadura laser de chapa fina como o desalinhamento e da soldadura laser de chapa galvanizada como os poros e a volatilização do zinco. Por fim apresentam-se resultados dá avaliação da qualidade da soldadura do ponto de vista qualitativo através da norma DIN 8563, e do pontos de vista quantitativo através de ensaios de tracção, dureza e corrosão.
\end{abstract}

Palavras clave: Soldadura laser, aço galvanizado, chapa fina.

\section{Thin-sheet zinc-coated and carbon steels laser welding}

\begin{abstract}
This paper describes the results of a research on $\mathrm{CO}_{2}$ laser welding of thin-sheet carbon steels (zinccoated and uncoated), at several thicknesses combinations. Laser welding has an high potential to be applied on sub-assemblies welding before forming to the automotive industry - tailored blanks.

The welding process is studied through the analysis of parameters optimization, metallurgical quality and induced distortions by the welding process. The clamping system and the gas protection system developed are fully described. These systems allow the minimization of common thin-sheet laser welding defects like misalignement, and zinc-coated laser welding defects like porous and zinc volatilization. The laser welding quality is acessed by DIN 8563 standart, and by tensile, microhardness and corrosion tests.
\end{abstract}

Keywords: Laser welding. Zinc coated steel. Thin thickness sheets.

\section{INTRODUÇÃO}

A tecnologia laser aplicada à operação de soldadura, apresenta vantagens significativas, comparativamente a outros processos de união de materiais, ditos convencionais. A soldadura laser permite a realização de uniões de elevada qualidade, minimizando os níveis de entrega

(*) Instituto de Soldadura e Qualidade. (Portugal).

(**) Instituto Superior Técnico-Secção de Tecnologia Mecânica (Portugal). térmica ao material, sendo possível atingir velocidades de soldadura elevadas.

Estas características tornaram possível uma vasta gama de aplicações da soldadura laser, em vários sectores industriais. A indústria automóvel é o sector que alberga maior número de aplicações, e equipamentos, devido à sua capacidade de rentabilizar o investimento elevado num sistema de soldadura laser. Para além de aplicações na área de soldadura de componentes de um veículo (cablagens, tanques de combustível, sistema de escape, caixas de velocidades, etc.), uma das grandes áreas de interesse é a soldadura de painéis 
de carroçaria. O processo de soldadura laser tem vindo substituir a soldadura por resistência(1),visto garantir maiores velocidades de soldadura, maior tenacidade da estrutura soldada, e maior facilidade de aplicação, uma vez que não necessita de acesso dos dois lados da chapa.

Por forma a reduzir o peso dos veículos, a indústria automóvel desenvolveu há cerca de 10 anos(2) uma nova metodologia de fabrico de painéis de carroçaria. Esta metodologia substitui painéis constituídos por um só tipo de material e espessura, por painéis constituídos por retalhos de chapas de diferentes espessuras e materiais. Esta metodologia começou por ser utilizada com soldadura por resistência com roletes, o qual não é ideal para esta aplicação, uma vez que tem de ser utilizada junta sobreposta. A soldadura laser tem vindo a ser cada vez mais utilizada nesta aplicação, tendo a vantagem de permitir a soldadura topo a topo. No entanto, a sua aplicação não se tem alargado porque subsistem alguns problemas.

\section{PROBLEMAS A RESOLVER NA INVESTIGAÇÃO}

As espessuras envolvidas neste tipo de painéis, menores que $2 \mathrm{~mm}$, acarretam problemas de fixação e alinhamento, uma vez que no processo laser não existe a pressão dos eléctrodos tal como acontece na soldadura por resistência. Por forma a minimizar o desalinhamento, utilizam-se potências laser baixas, o que limita a velocidade de soldadura.

A preparação da junta assume, na soldadura laser de chapa fina, um papel importante devido à reduzida dimensão da zona de interacção feixe/matéria (cerca de $0,1 \mathrm{~mm}$ de diâmetro). Este facto leva à utilização de uma preparação de junta despendiosa (maquinagem), ou à utilização do feixe laser "desfocado", de forma a aumentar a dimensão da zona de interacção, o que diminui a densidade de energia disponível, limitando a velocidade de soldadura.

Com a crescente utilização de aço galvanizado na constituição destes painéis, surgiu outra limitação da aplicação da soldadura laser nesta metodologia de fabrico. Este material é cada vez mais utilizado pelos construtores de automóveis, uma vez que permite, com espessuras inferiores, garantir níveis elevados de resistência à corrosão. Devido aos problemas de volatilização do zinco e à formação de um plasma absorvente da radiação laser, este material é considerado como de má soldabilidade quanto soldadura laser.

O trabalho experimental apresentado neste artigo, pretende investigar o comportamento à soldadura por laser de $\mathrm{CO}_{2}$, de chapa fina de aço carbono e aço galvanizado, em várias combinações de espessura e materiais. Pretende-se estabelecer o procedimento de soldadura em modo keyhole para espessuras inferiores a $1,5 \mathrm{~mm}$, utilizando para isso uma potência laser, $2 \mathrm{~kW}$, considerada elevada para as espessuras em causa. O procedimento terá de garantir que se obtêm cordões de soldadura com níveis de qualidade aceitáveis dos pontos de vista mecânico, metalúrgico e resistência à corrosão e da integridade geométrica.

Devido aos materiais envolvidos, gama de espessuras e combinações de espessuras que se pretendem soldar, com o objectivo de maximizar as velocidades de processamento, terão de ser enfrentados os seguintes problemas:

- formação de plasma inibidor da soldadura;

- empeno das chapas inerente às espessuras envolvidas;

- preparação de junta não ideal (corte laser);

e criadas as condições para:

- formação de keyhole;

- redução de custos de consumo de gás;

- minimização da volatilização do zinco.

Por forma a ultrapassar os problemas referidos, será necessário investigar o processo por forma a desenvolver:

- sistema de protecção gasosa que iniba a formação de plasma e possibilite a soldadura por keyhole, minimizando os consumos de gás;

- sistema de fixação das chapas que elimine os desalinhamentos, ou os diminua para níveis aceites pelas normas de qualificação das soldaduras;

- procedimento de soldadura (combinação paramétrica) que garanta velocidades competitivas e integridade das soldadura efectuadas (do ponto de vista de resistência mecânica e resistência à corrosão).

\section{TRABALHO EXPERIMENTAL}

Foram seleccionados dois tipos de materiais bastante utilizados nos componentes de carroçaria de automóveis, cujas espessuras são normalmente inferiores a $1,5 \mathrm{~mm}$. As espessuras seleccionadas e a designação dos aços está indicada na tabela 1 . Por forma a ultrapassar os problemas identificados no ponto anterior, desenvolveram-se dois sistemas: um sistema de protecção gasosa e um sistema de fixação das chapas. 
TABELA I.- Materiais, espessuras e composição química do material a ensaiar.

TABLE I.-Codes, thicknesses and composition of the steels used.

\begin{tabular}{|l|c|c|c|c|c|l|l|}
\hline Designação & $\% \mathrm{C}$ & $\% \mathrm{Si}$ & $\% \mathrm{Mn}$ & $\% \mathrm{P}$ & $\% \mathrm{~S}$ & Revestimento Zn & Espessuras \\
\hline St 1203 & 0,10 & 0,15 & 0,32 & $<0,040$ & $<0,040$ & - & 1,25 e $0,75 \mathrm{~mm}$ \\
St $02 \mathrm{Z}$ & 0,10 & 0,15 & 0,32 & $<0,040$ & $<0,040$ & $7.1 \mu \mathrm{m}$ & 1,$25 ; 0,75$ e $0,5 \mathrm{~mm}$ \\
\hline
\end{tabular}

O sistema de protecção gasosa foi desenvolvido com o objectivo de inibir a formação de plasma no topo da soldadura, possibilitando ao mesmo tempo a soldadura em modo keyhole, por forma a atingirem-se elevadas velocidades de soldadura.

O sistema de fixação de chapas desenvolvido, tem como objectivo evitar defeitos de desalinhamento, garantindo a não deformação das chapas durante o processo de soldadura.

\subsection{Sistema de protecção gasosa}

Em geral os sistemas de eliminação de plasma, são baseados em jactos oblíquos. Estes sistemas não são eficientes, uma vez que são muito sensíveis a pequenas variações de caudal e de ângulo de ata-

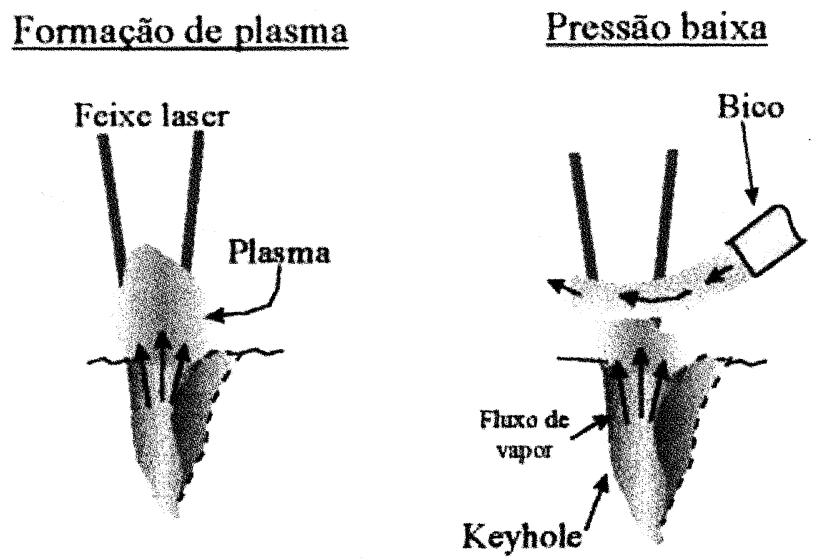

que(3). Além disso, quando se altera a espessura do material, ou a geometria da junta, há que "calibrar" outra vez a posição deste jacto. Este tipo de jactos têm sido alvo de estudo por vários investigadores, entre os quais se destaca ARATA, que recorreu a câmaras de alta velocidade. Os seus resultados podem ser resumidos no esquema presente na fig.1.

Em última análise, o sistema de inibição do plasma, deve prevenir a formação de plasma, sem induzir defeitos na soldadura. Para que exista um plasma estável, torna-se necessário haver alimentação constante de novos átomos ou moléculas para serem ionizadas(3). O sistema desenvolvido baseia-se na criação de uma perturbação na zona de interacção feixe/material de forma a dispersar o material ionizado, e deste modo impedir a formação de plasma.

\section{Pressão correcta Grande afastamento bico peca}
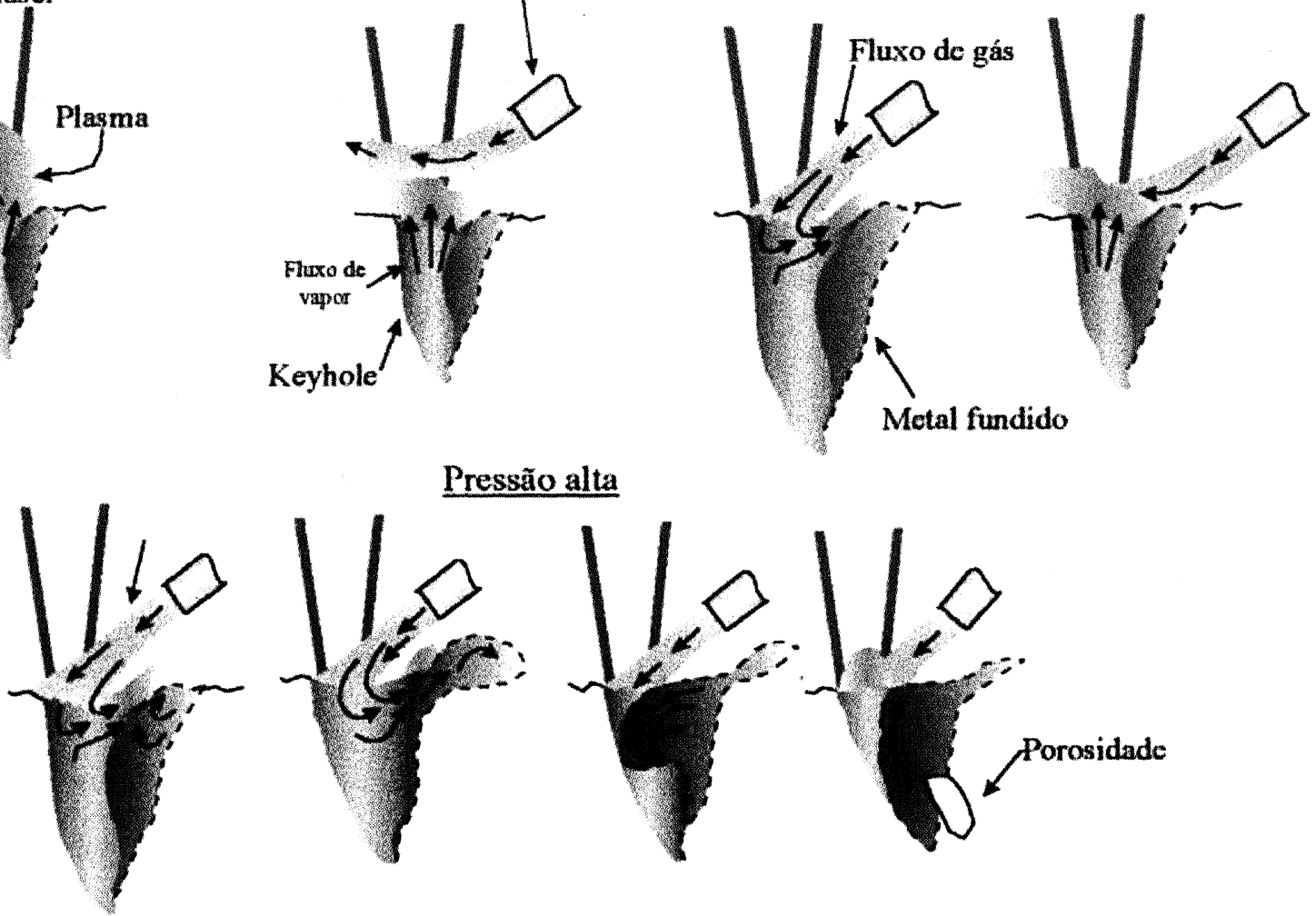

\section{Pressão alta}
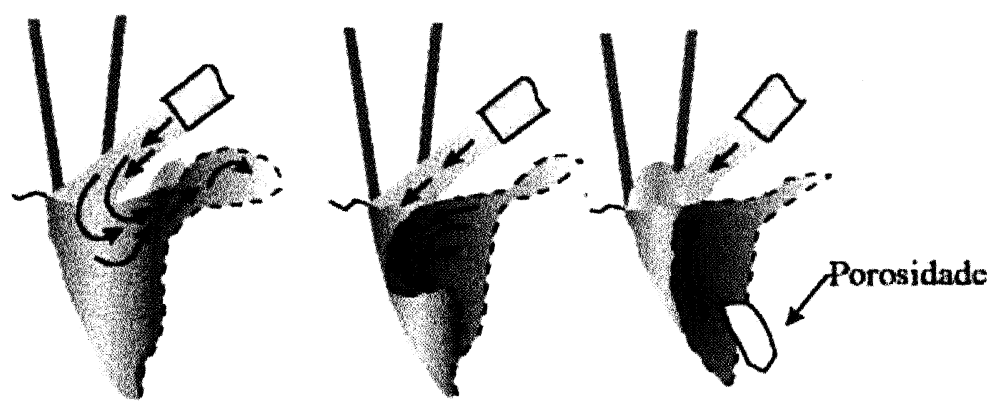

FIG. 1.- Esquema de interacção entre plasma, gás inibidor de plasma e banho em fusão(3). FIG. 1.-Interaction between plasma, gas stream and melted zone. 
O sistema de protecção gasosa, ou de inibição de plasma, desenvolvido (fig.2) é constituído por uma caixa rectangular com cerca de $60 \times 120 \mathrm{~mm}$, estando a sua parte inferior repleta de orifícios de $1,5 \mathrm{~mm}$ de diâmetro, espaçados de $2 \mathrm{~mm}$. Colocando esta caixa de forma a que esta "rede" fique ao nível do bico de soldadura, e injectando um dado fluxo de gás na caixa, geram-se multiplos fluxos de gás que originam uma elevada turbulência na zona. É evidente que esta turbulência poderá afectar o fluxo de gás coaxial, o qual é fundamental para a formação do keyhole. Por forma a minimizar este efeito, a soldadura deve ser realizada com o bico de pequeno diâmetro bastante perto da chapa. Utilizou-se um bico de $2,0 \mathrm{~mm}$ de diâmetro a uma distância de $2 \mathrm{~mm}$. Com estes valores houve necessidade de desenhar um bico, que
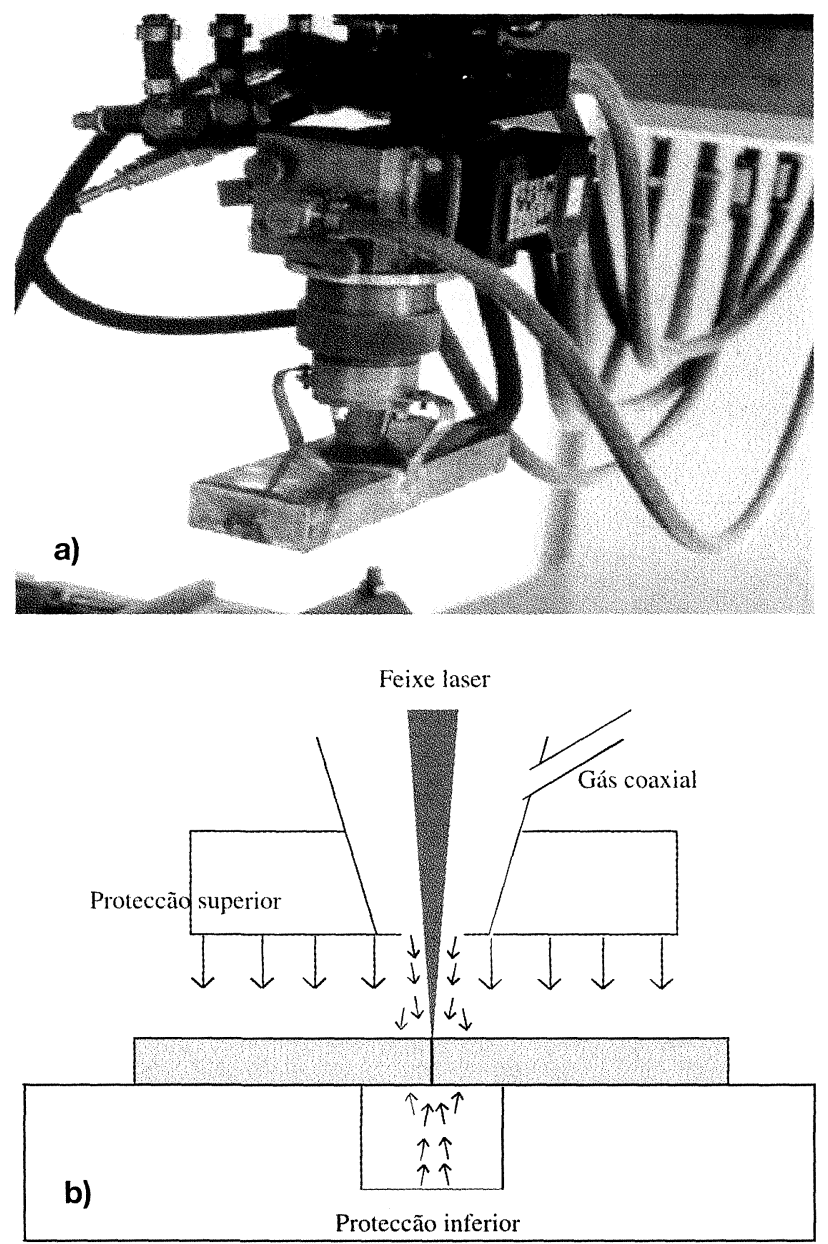

FIG. 2.- Sistema de protecção gasosa, que permite inibir também a formação de plasma. a) Sistema de protecção acopolado à cabeça. Caixa com $60 \times 120 \mathrm{~mm}$, sendo perfurada por baixo com uma malha de furos de $1,5 \mathrm{~mm}$ de diâmetro espaçados de $2 \mathrm{~mm}$. b) Esquema da protecção gasosa.

FIG. 2.-Developed gas shielding device, also prevents the plasma formation. a) Gas boxe integrated with the laser nozzle. b) Scheme of the gas shielding device. permitisse a passagem do feixe mas que tivesse uma abertura de 2,0 $\mathrm{mm}$.

\subsection{Sistema de fixação}

A utilização de sistemas mecânicos de fixação de chapa, condiciona o nível de qualidade das soldaduras quando estão envolvidas chapas de pequena espessura (4) (5) (6), sendo o desalinhamento o tipo de defeito mais comum. A ocorrência deste defeito deve-se essencialmente, à ineficiência dos sistemas de fixação, que não corrigem a não planicidade da chapa. Devido ao processo de laminagem a frio as chapas finas apresentam deformações inerentes ao elevado nível de tensões internas.

Surge a necessidade de desenvolver um novo sistema de fixação que garanta uma carga suficiente ao longo de toda a extensão do cordão de soldadura e o mais perto possível da junta. Como os sistemas mecânicos não garantem uma distribuição de carga uniforme, pois existem sempre zonas de aperto onde a carga é máxima, optou-se por desenvolver um sistema de fixação baseado em magnetes.

O sistema de fixação desenvolvido, fig.3, possibilita um fácil posicionamento das chapas, exercendo uma pressão uniforme de $2000 \mathrm{MPa}$ até muito perto da junta de soldadura $(3 \mathrm{~mm})$. Este valor de pressão é de longe superior às tensões residuais das chapas, uma vez que a tensão de cedência de um aço com $0,1 \%$ de carbono é inferior a $500 \mathrm{MPa}$.

A utilização desta pressão deverá inibir o aparecimento de desalinhamentos significativos, no entanto, poderão surgir ligeiros desalinhamentos devido a um pequeno troço de $3 \mathrm{~mm}$ de chapa que não está sujeito ao campo magnético.

\subsection{Parâmetros e sistemas utilizados}

Para a realização dos ensaios utilizou-se um laser de $\mathrm{CO}_{2}$ de fluxo axial rápido (Rofin Sinar 2500RF) e descarga por radio-frequência, com potência nominal de $2,5 \mathrm{~kW}$ e de modo $\mathrm{TEM}_{20}$. Nestes ensaios utilizou-se um espelho parabólico de cobre, com revestimento de ouro, cujo comprimento focal é de $127 \mathrm{~mm}$, resultando um diâmetro do feixe no ponto focal de $0,156 \mathrm{~mm}$.

Como gás de proteç̧ão na raíz utilizou-se argon com um caudal de $20 \mathrm{l} / \mathrm{min}$, uma vez que a sua função é não permitir a entrada de ar que contamine o cordão na raíz. Para testar a eficiência do sistema de protecção gasosa superior (sistema de inibição de plasma) utilizou-se também argon com o mesmo caudal. A presença de argon perto da zona de 

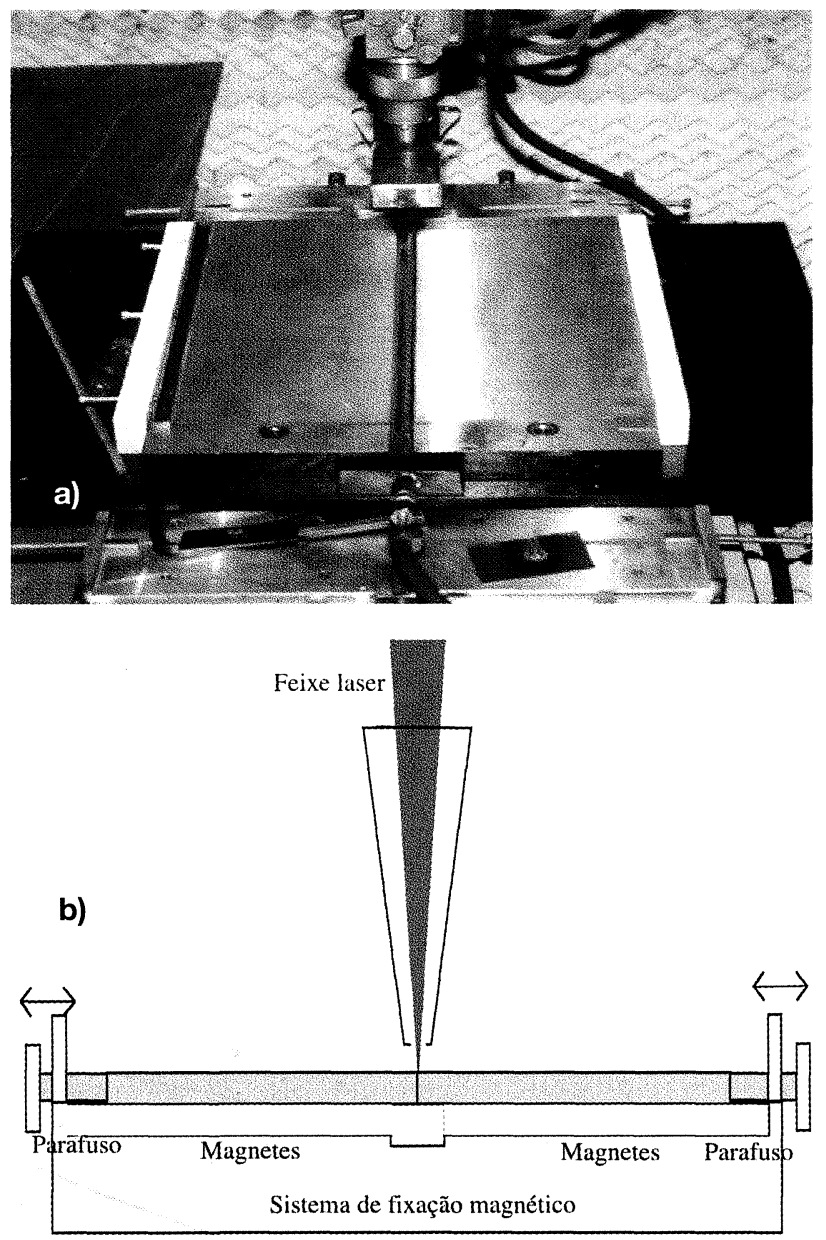

FIG. 3.- (a) Sistema de Fixação magnético. A força exercida pelos magnetes é de $2000 \mathrm{MPa}$. (b)

Esquema do sistema de fixação magnético.

FIG. 3.- (a) Magnetic clamping system. The strength applied is about 2.000 MPa. (b) Scheme of the magnetic clamping device.

soldadura pode trazer problemas, uma vez que poderá sob certas condições vir a formar plasma. No entanto, o sistema desenvolvido não injecta o gás directamente no feixe laser, pelo que se optou pela utilização de argon em vez de hélio, pois o seu custo é muito inferior. Deste modo também será possível verificar se a existência de um escoamento turbulento, mesmo de argon, inibe a formação de plasma. Como gás coaxial testou-se o hélio com caudais entre 12 e $25 \mathrm{l} / \mathrm{min}$.

Relativamente à posição do ponto focal utilizaram-se três posicionamentos distintos para cada espessura: posicionamento imediatamente abaixo da superfície $(-0,2 \mathrm{~mm})$, a cerca de metade da espessura e perto da raíz. Em geral o processo de soldadura laser não é sensível a variações de posicionamento do ponto focal inferiores a $0,5 \mathrm{~mm}$. No entanto como se trata de chapa fina, testaram-se pontos focais em várias posiçõs relativas à espessura da chapa.
Nos ensaios utilizaram-se dois tipos de preparação de junta. As superfícies maquinadas foram preparadas por rectificação, garantindo-se uma precisão da inclinação da superfície de corte de $+/-0,025 \mathrm{~mm}$. Os valores de rugosidade média foram medidos em quatro amostras para cada material e espessura, utilizando um rugosímetro com sensibilidade entre 0,100 e $0,001 \mathrm{~mm}$, estando os valores médios apresentados na tabela 2 . Para a preparação das superfícies de corte laser, utilizou-se o mesmo laser dos ensaios de soldadura, com uma potência de $1000 \mathrm{~W}$, utilizando oxigénio como gás de assistência. Por forma a determinar a qualidade dos cortes efectuados, mediu-se a inclinação da superfície de corte, $\mathrm{u}$, e a rugosidade média, $\mathrm{R}_{\mathrm{z}}$. Pode-se inferir que a qualidade dos corte obtidos é elevada, devendo à partida pemitir a soldadura laser, uma vez que a distância máxima entre chapas originada pelas características da superfície é de $0,098 \mathrm{~mm}(2 \times 0,049 \mathrm{~mm})$, e o diâmetro do feixe laser no ponto focal é de $0,156 \mathrm{~mm}$.

TABÉLA 2.- Valores de rugosidade e ortogonalidade das superfíces de corte das chapas utilizadas nos ensaios.

TABLE 2.- Roughness and squareness values of the laser cut sheets.

\begin{tabular}{|l|l|l|l|l|l|l|l|}
\hline & Material & & St 1203 & & St 02Z & & \\
\hline & Espessura & $(\mathrm{mm})$ & 1,25 & 0,75 & 1,25 & 0,75 & 0,5 \\
\hline Corte laser & $\mathrm{R}_{\mathrm{Z}}$ & $(\mathrm{mm})$ & 0,022 & 0,012 & 0,017 & 0,017 & 0,018 \\
\cline { 2 - 8 } & $\mathrm{u}$ & $(\mathrm{mm})$ & 0,031 & 0,033 & 0,044 & 0,049 & 0,034 \\
\hline Rectificado & $\mathrm{R}_{\mathrm{z}}$ & $(\mathrm{mm})$ & $<0,001$ & $<0,001$ & $<0,001$ & $<0,001$ & $<0,001$ \\
\hline
\end{tabular}

Realizaram-se cordões de soldadura de $300 \mathrm{~mm}$ de comprimento, utilizando o sistema de fixação desenvolvido, sendo a chapas posicionadas por forma a não haver afastamento.

\section{DISCUSSÃO DE RESULTADOS}

Com os sistemas desenvolvidos foi possível obter cordões de soldadura de elevada qualidade, em todas as combinações de materiais e espessuras. Os cordões não exibem oxidação superficial e têm um aspecto visual regular ao longo dos $300 \mathrm{~mm}$ de cordão (fig.4). Foi possível observar a formação de keyhole em todas as soldaduras, o que permitiu atingir velocidades de soldadura elevadas (tabela 3 ). Estes factos revelam que o sistema de protecção gasosa é eficiente, na inibição de plasma e na protecção do cordão.

Dos testes realizados com o sistema de protecção gasosa desenvolvido, observou-se que o caudal de hélio não influenciou a velocidade de soldadura, permitindo assumir um caudal óptimo de 
hélio de $15 \mathrm{l} / \mathrm{min}$. Este valor é francamente inferior aos caudais de hélio utilizados nos sistemas de protecção gasosa convencionais (entre 25 e 30 $1 / \mathrm{min}$ ), pelo que o sistema desenvolvido tem benefícios económicos ao nível do consumo do gás significativos. Nos sistemas convencionais utilizamse caudais de hélio elevados devido à baixa densidade deste gás, no entanto neste caso utiliza-se um bico de pequeno diâmetro e uma pequena distância bico/peça, que minimizam eventuais perturbações no fluxo de gás coaxial.

O posicionamento do ponto focal a $0,2 \mathrm{~mm}$ de distância da superfície da chapa garante a maximização da velocidade. No caso das espessuras dissimilares, o ponto focal deve ser colocado a cerca de $0,2 \mathrm{~mm}$ de distância da superfície da chapa menos espesssa.

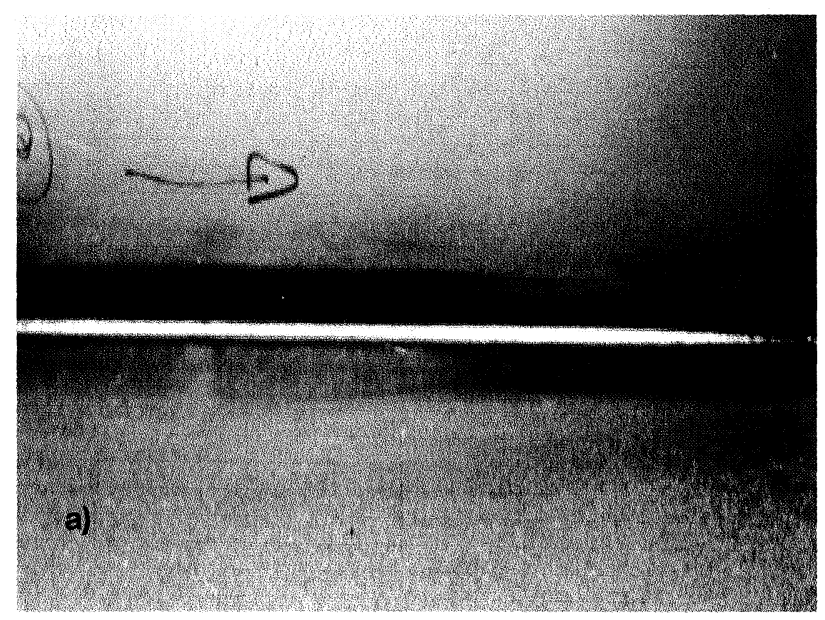

\subsection{Avaliação qualitativa das soldaduras efectuadas}

De forma a determinar a qualidade das soldaduras efectuadas, realizaram-se ensaios radiográficos e metalográficos, segundo a norma EN ISO 13919-1. Pretende-se com esta análise confirmar, ou não, os resultados da observação visual das soldaduras. Caso se detectem problemas metalúrgicos, poros ou fendas, ou defeitos geométricos, significa que os parâmetros determinados terão de ser corrigidos.

O objectivo de utilização da norma EN referida, é identificar numa análise breve e com baixos custos a presença de defeitos geométricos ou metalúrgicos, que inibam um bom desempenho das soldaduras, evitando a realização de ensaios mais

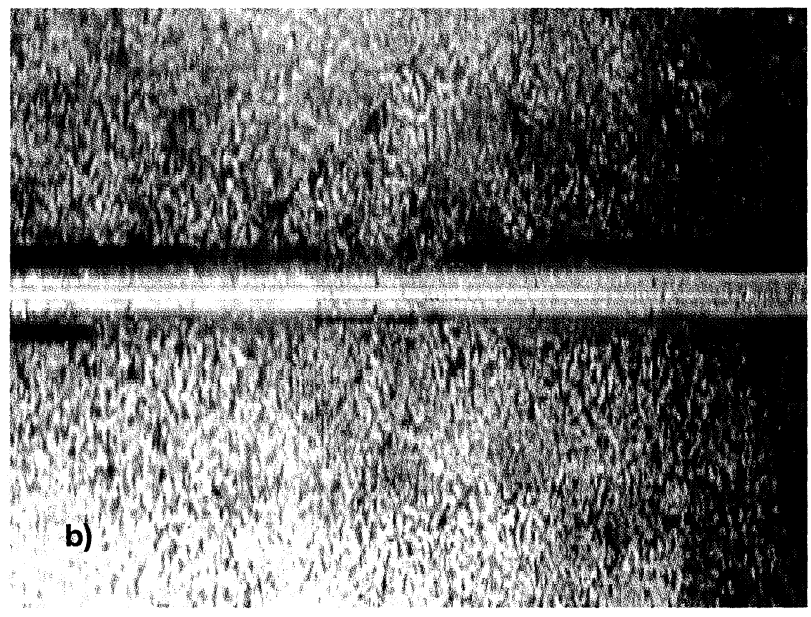

Fig. 4.- Fotografia de dois cordões de soldadura, onde é possível observar a inexistência de oxidação a) Aço carbono 1,25 mm b) Aço galvanizado 1,25 $\mathrm{mm}$ de espessura.

FIG 4.- Oxidation-free weld beads, performed with the developed gas shielding device a) Carbon steel 1,25 $\mathrm{mm}$ b) Zinc-coated steel 1,25 $\mathrm{mm}$

TABELA 3.- Parâmetros óptimos que maximizam velocidade, utilizando o sistema de fixação magnético.

TABLE 3.- Optimum parameters for speed maximization, using the magnetic clamping system.

\begin{tabular}{|c|c|c|c|c|c|c|c|}
\hline $\begin{array}{c}\text { Espessura } \\
(\mathrm{mm})\end{array}$ & Material & Parâmetros & \begin{tabular}{|c|} 
St 1203 \\
$1,25 \mathrm{~mm}$
\end{tabular} & \begin{tabular}{|c|} 
St $02 Z$ \\
$1,25 \mathrm{~mm}$
\end{tabular} & $\begin{array}{c}\text { St } 1203 \\
0,75 \mathrm{~mm}\end{array}$ & $\begin{array}{c}\mathrm{St} 02 \mathrm{Z} \\
0,75 \mathrm{~mm}\end{array}$ & $\begin{array}{c}\text { St } 02 Z \\
0,5 \mathrm{~mm}\end{array}$ \\
\hline \multirow[t]{4}{*}{$1,25 \mathrm{~mm}$} & \multirow[t]{2}{*}{ St 1203} & Velocidade $(\mathrm{mm} / \mathrm{min})$ & 3000 & 3000 & 3000 & 3000 & 3000 \\
\hline & & P. focal $(\mathrm{mm})$ & $-0,2 \mathrm{~mm}$ & $-0,2 \mathrm{~mm}$ & $-0,5 \mathrm{~mm}$ & $-0,5 \mathrm{~mm}$ & $-1,0 \mathrm{~mm}$ \\
\hline & \multirow[t]{2}{*}{ St $02 Z$} & Velocidade $(\mathrm{mm} / \mathrm{min})$ & & 3000 & 3000 & 3000 & 3000 \\
\hline & & P. focal $(\mathrm{mm})$ & & $-0,2 \mathrm{~mm}$ & $-0,5 \mathrm{~mm}$ & $-0,5 \mathrm{~mm}$ & $-1,0 \mathrm{~mm}$ \\
\hline \multirow[t]{4}{*}{$9,75 \mathrm{~mm}$} & \multirow[t]{2}{*}{ St 1203} & Velocidade $(\mathrm{mm} / \mathrm{min})$ & & & 4200 & 4200 & 4200 \\
\hline & & P. focal (mm) & & & $-0,2 \mathrm{~mm}$ & $-0,2 \mathrm{~mm}$ & $-0,5 \mathrm{~mm}$ \\
\hline & \multirow[t]{2}{*}{ St $02 Z$} & Velocidade $(\mathrm{mm} / \mathrm{min})$ & & & & 4200 & 4200 \\
\hline & & P. focal (mm) & & & & $-0,2 \mathrm{~mm}$ & $-0,5 \mathrm{~mm}$ \\
\hline \multirow[t]{2}{*}{$0,5 \mathrm{~mm}$} & \multirow[t]{2}{*}{ St $02 Z$} & Velocidade $(\mathrm{mm} / \mathrm{min})$ & & & & & 6750 \\
\hline & & P. focal $(\mathrm{mm})$ & & & & & $-0,2 \mathrm{~mm}$ \\
\hline
\end{tabular}




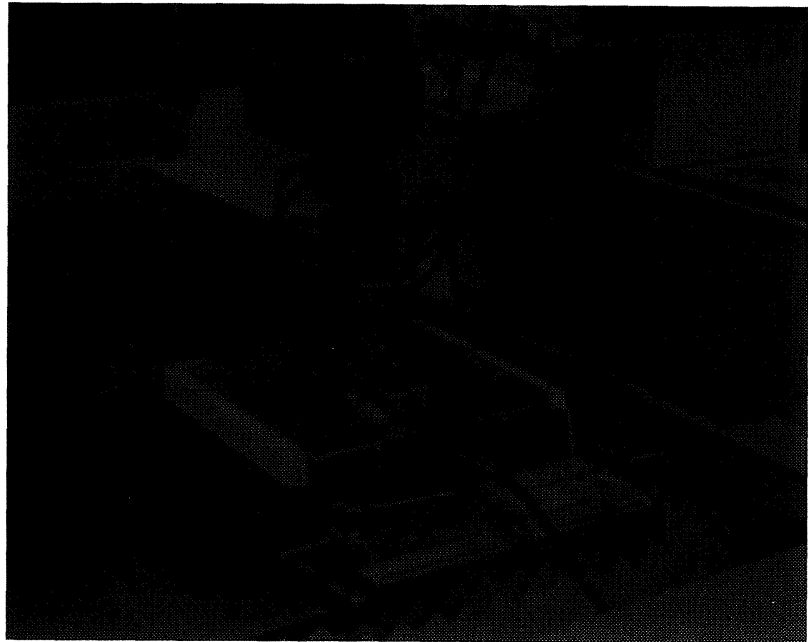

FIG. 5.- Execução de soldadura em que é possível visualisar-se a formação de keyhole.

FIG. 5.- Laser welding process with keyhole observation.

despendiosos (ensaios mecâni-cos). A soldadura laser tem características únicas ao nível do cordão de soldadura, surgindo com muito mais frequência certo tipo de defeitos, do que em relação a outros processos de soldadura. Este facto verifica-se ainda mais nas espessuras pequenas, como é o caso deste trabalho. A norma baseia-se em duas análises: ensaio de R-X, por forma a identificar a presença de poros e/ou defeitos lineares internos; e análise metalográfica, com ampliação macro, por forma a se identificarem defeitos geométricos no cordão. Através da quantificação da quantidade e dimensão destes defeitos, a norma permite qualificar a soldadura num de quatro níveis:

- nível B: qualidade máxima

- nível C: qualidade média

- nível D: qualidade medíocre

- nível E: inaceitável

$\mathrm{Na}$ tabela 4 estão indicados os defeitos identificados pela norma e em esquema o modo de medição. Os valores de aceitação não são absolutos, mas sim relativos à espessura. Indicam-se os valores máximos admitidos para soldaduras com qualidade B, visto ser esta a qualidade que se pretende atingir nas soldaduras efectuadas.

A norma refere cerca de 18 tipos de defeitos. As imperfeições 1 a 8 (tabela 4) podem ser identificadas/quantificadas através da análise por RX. Os defeitos 9 a 18 (tabela 4) são quantificados a partir de uma imagem de macrografia, com ampliação de cerca de 40x.

TABELA 4.- Tabela resumo do conteúdo da norma EN ISO 13919, que permite classificar qualitativamente a soldadura.

TABLE 4.- Summary of EN ISO 13919 standart for the laser welding evaluation.

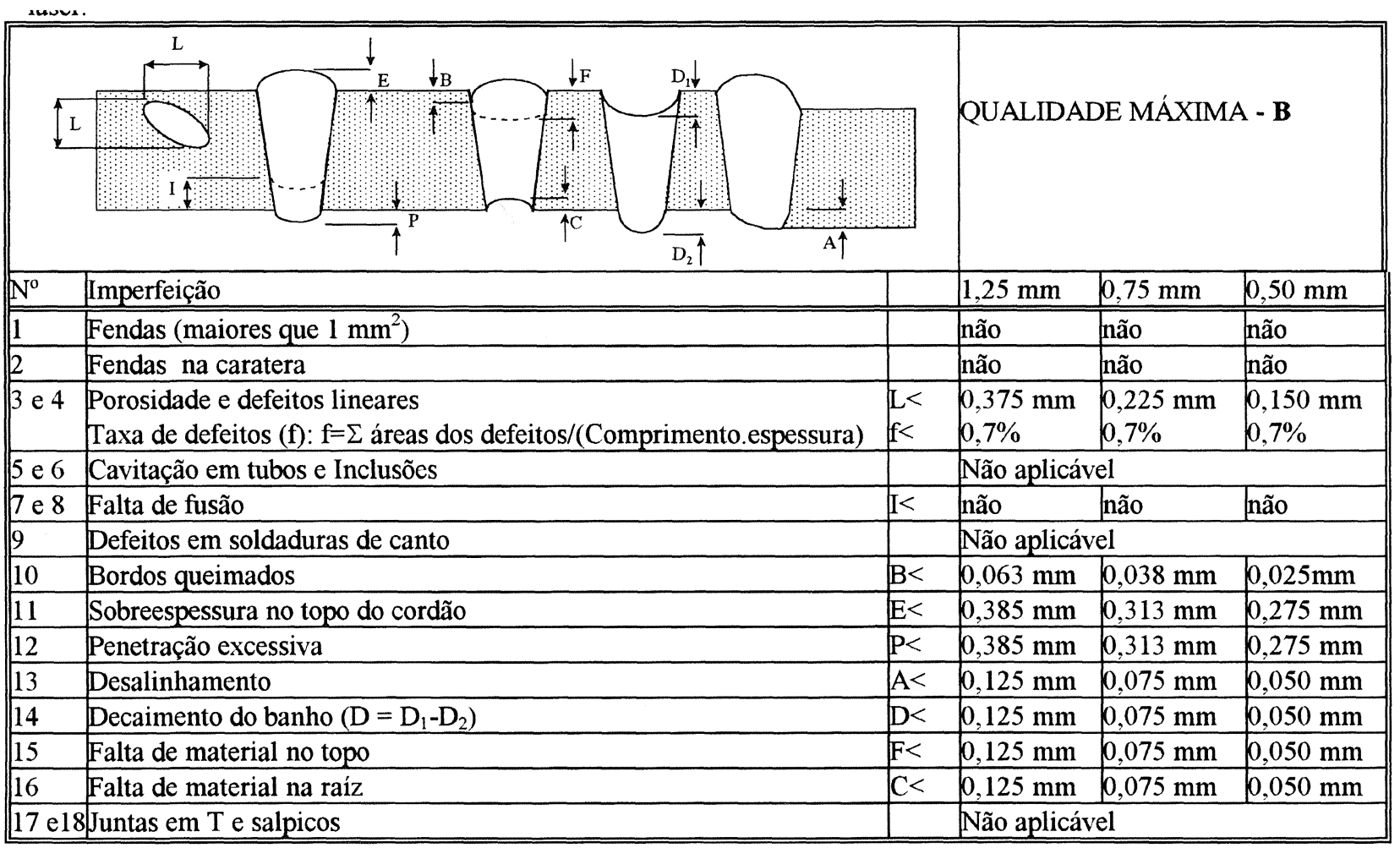


A norma é conservativa, no sentido em que, se apenas um defeito for classificado com $\mathrm{C}$ e os outros todos com B, a soldadura é classificada com um C. Da análise das radiografias e das macrografias foi possível aplicar a norma EN ISO 13919-1, estando os resultados apresentados nas tabelas 5 e 6 .
Enquanto que no caso das espessuras de 0,75 e $1,25 \mathrm{~mm}$, todas as amostras apresentaram qualidade máxima (B), para a espessura de $0,5 \mathrm{~mm}$, subsistiu a ocorrência de alguns pequenos defeitos. Por forma a ilustrar este facto, seleccionaram-se essas amostras para apresentar nas tabelas 5 e 6 . A presença destes defeitos, leva a concluir que a

TABELA 5.- Espessuras similares - Resultado da aplicação da norma às soldadura efectuadas. A vermelho é indicado o defeito responsável por a soldadura não apresentar qualidade $\mathrm{B}$, a azul estão indicados os defeitos identificados mas cuja presença mantém a soldadura na qualidade B.

TABLE 5.- Similar thicknesses laser welding macros.

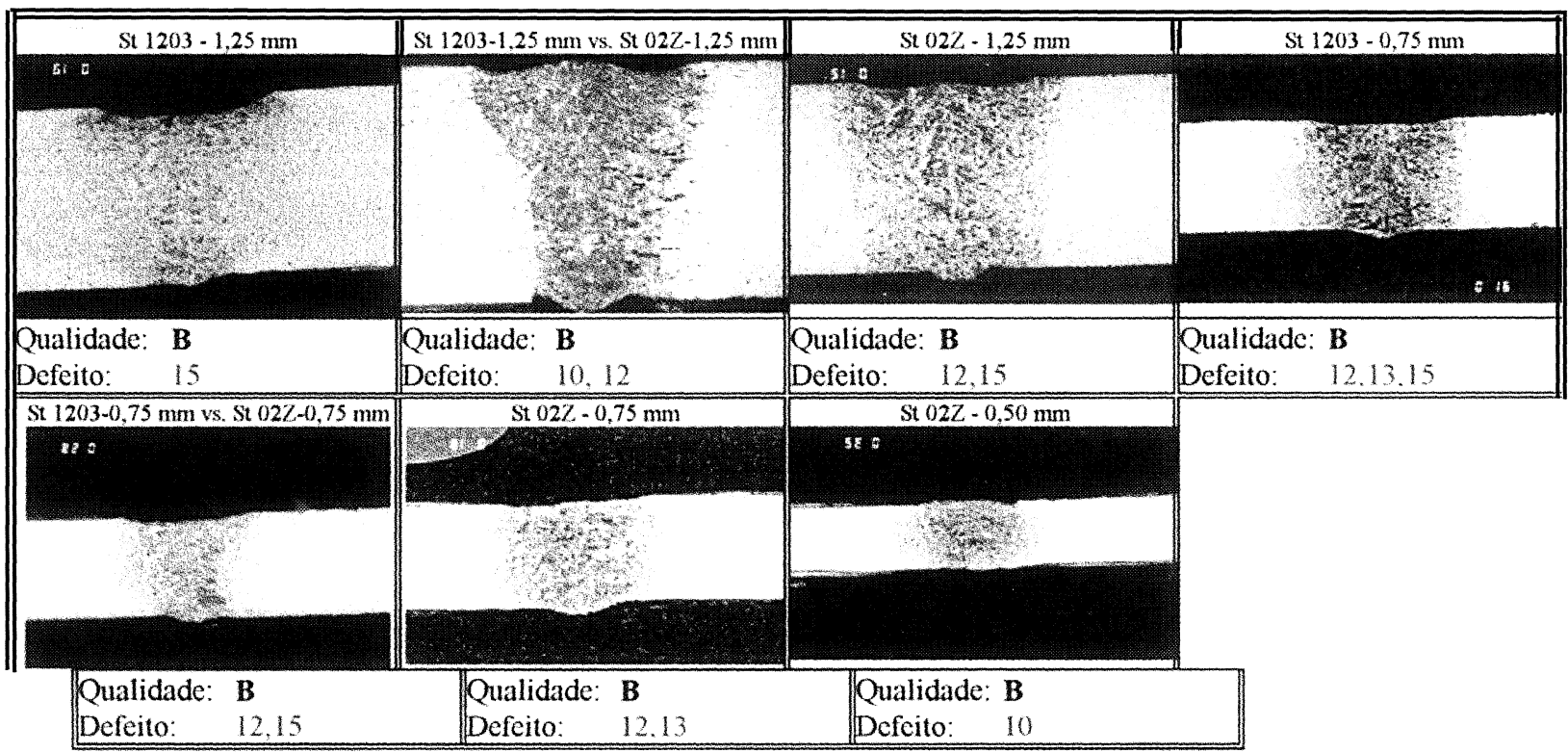

Legenda: 10: Bordos queimados;12: Penetraçäo excessiva ; 13: Desalinhamento; 14: Decaimento do banho;15: Falta de material no topo.

TABELA 6.- Espessuras dissimilares - Resultado da aplicação da norma às soldadura efectuadas. A vermelho é indicado o defeito responsável por a soldadura não apresentar qualidade $\mathrm{B}$, a azul estão indicados os defeitos identificados mas cuja presença mantém a soldadura na qualidade B.

TABLE 6.- Different thicknesses laser welding macros.

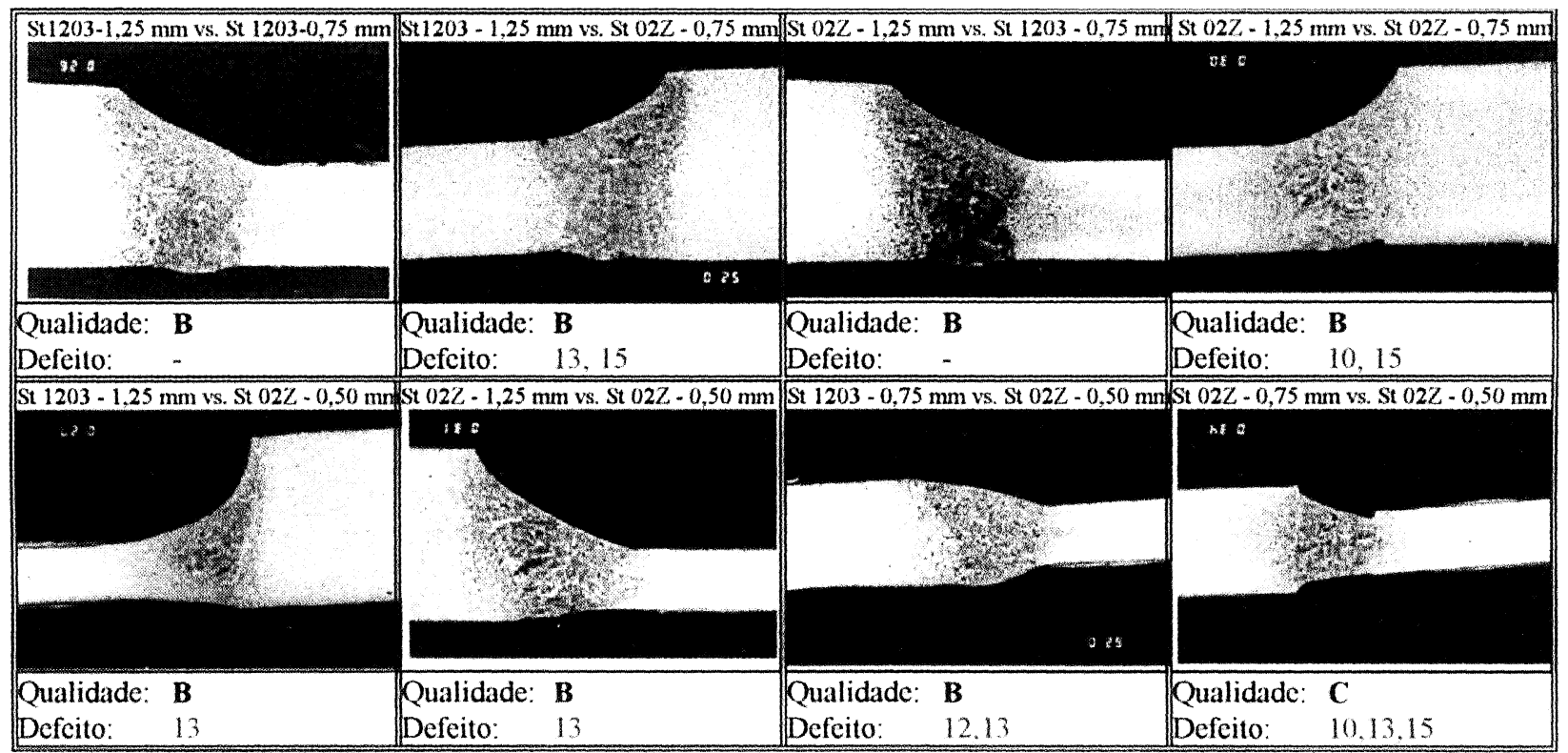

Legenda: 10: Bordos queimados; 11: Sobreespessura ; 12: Penearaçáo excessiva; 13: Desalinhamento; 14: Decaimento do banho; $15:$ Falta de material no topo. 
chapa de $0,5 \mathrm{~mm}$ é mais sensível ao fenómeno de libertação de tensões residuais, uma vez que a secção resistente é menor (menor espessura). No entanto, os defeitos originados são de pequena magnitude, pemitindo que as soldaduras atingam um nível de qualidade médio (C). A influência destes defeitos nas propriedades mecânicas será avaliada nos ensaios mecânicos realizados.

\subsection{Avaliação das características metalúrgicas $e$ de resistência mecânica e à corrosão das soldaduras}

As soldaduras de chapa de aço galvanizado não apresentaram poros ou outros defeitos interiores, típicos da soldadura destes aços. Isto deve-se essencialmente ao facto de se utilizar um sistema de inibição de plasma que não injecta gás oblíquo ao banho de soldadura, evitando a introdução de zinco na zona fundida.

$\mathrm{Na}$ análise metalográfica observou-se a presença de martensite na zona fundida e na zona termicamente afectada. Os ensaios de microdureza realizados na superfiície transversal dos cordões apontam para durezas destas zonas inferiores a 300 HV1, pelo que a martensite presente não origina a fragilidade da zona soldada.

A largura dos cordões obtidos é da ordem de grandeza da espessura da chapa, o que é um valor típico da soldadura laser de chapa fina, em modo keyhole. A extensão da zona termicamente afectada é inferior a $0,2 \mathrm{~mm}$, o que se deve às elevadas velocidades de soldadura atingidas.

Realizaram-se ensaios de tracção, tendo-se verificado em todos os provetes a ruptura no material base, o que confirma a elevada qualidade das soldaduras.

Devido às elevadas velocidades de soldadura atingidas a camada de zinco volatilizada restringese ao cordão de soldadura. Na zona adjacente ao cordão observou-se uma camada de zinco fundida, com uma extensão que não ultrapassa os $2 \mathrm{~mm}$, sendo regular ao longo de todo o cordão

Por forma a avaliar a resistência à corrosão das soldadura efectuadas emergiram-se as amostras numa solução de $1 \%$ de $\mathrm{NaCl}$ a $100^{\circ} \mathrm{C}$, sendo observadas ao longo de vários intervalos de tempo: $1,4,8,16,24,72$ e 120 horas. Estes ensaios só foram realizados para as soldaduras que envolveram aço galvanizado. Com este ensaio é possível comparar a resistência dos cordões de soldadura com a do material base. O objectivo é analisar o efeito da vaporização da camada de zinco que ocorreu devido à realização do cordão de soldadura. Este teste permitiu também avaliar qual a protecção corrosiva da camada de zinco fundida detectada.
Verificou-se que ao fim da primeira hora o grau de corrosão era intenso, mas a partir deste período o processo tende a estabilizar. Durante os vários períodos a zona do cordão e a ZTA não apresentavam maiores níveis de corrosão do que a zona galvanizada afastada da soldadura. No caso das soldaduras dissimilares, a zona adjacente à soldadura na chapa de aço carbono apresentou menos corrosão que o aço carbono de base, devido à proximidade da chapa galvanizada. No caso das soldaduras dissimilares, o aço carbono apresentou sempre um maior grau de corrosão que o aço galvanizado, o que sería de esperar.

Com este ensaio verificou-se que os cordões de efectuados apresentam um nível de resistência à corrosão semelhante à do aço galvanizado St $02 Z$, pelo que o processo de soldura laser não afecta esta propriedade. $\mathrm{O}$ facto de se formar a zona de zinco fundido adjacente ao cordão, restringe a zona desprotegida de zinco ao cordão de soldadura. Devido à pequena largura desta zona, o zinco continua a oferecer protecção catódica, não ocorrendo corrosão diferencial no cordão de soldadura.

\section{CONCLUSÕES}

Dos ensaios realizados com os sistemas desenvolvidos, pode-se inferir que:

- A utilização de escoamento turbulento na zona superior do banho de fusão, inibe a formação de plasma, não afectando a formação do keyhole, desde de que se minimize distância do bico à peça e se utilize um bico de pequeno diâmetro.

- O sistema de protecção gasosa desenvolvido, garante a formação do keyhole, com caudais de hélio como gás coaxial extremamente baixos: $15 \mathrm{l} / \mathrm{min}$, possibilitando a realização de cordões de soldadura a elevada velocidade (modo keyhole) e de elevada qualidade.

- Para além de assegurar baixos consumos de gás, o que é uma vantagem económica significativa, o sistema de protecção gasosa desenvolvido é de extrema utilidade em regime industrial, uma vez que não são necessárias calibrações ou regulações, para cada combinação de espessura e material, como é o caso dos sistemas de injecção oblíquos.

- A utilização de escoamento turbulento, em vez de um jacto oblíquo, para eliminar o plasma, permite a soldadura de aços galvanizados sem que ocorra a introdução de zinco no cordão, o que origina porosidades. Com o sistema de 
protecção gasosa desenvolvido, foi possível a execução de cordões de soldadura em chapa de aço galvanizado, sem que se tenham detectado poros ou fendas nos cordões de soldadura.

- O posicionamento do ponto focal que maximiza a velocidade de soldadura é a cerca de $0,2 \mathrm{~mm}$ da superfície. No caso da soldadura de espessuras dissimilares, a posição do ponto focal que maximiza a velocidade de soldadura é a cerca de 0,2 mm de distância da superfície da chapa mais fina.

- É possível efectuar cordões de soldadura, topo a topo, por laser de $\mathrm{CO}_{2}$ com elevada qualidade, utilizando o corte laser como preparação de junta, sem haver necessidade de desfocar o feixe para aumentar a zona de interacção.

- A eliminação de um dos defeitos típicos das soldaduras de chapa fina, o desalinhamento, torna-se possível através da utilização de um sistema de fixação que garanta um carga uniforme ao longo de toda a junta a soldar, e com níveis de pressão superiores à tensão de cedência do material. No presente trabalho, a utilização do sistema de magnetes desenvolvido, que exerce uma pressão de 2000 $\mathrm{MPa}$, garantiu uma carga uniforme ao longo da junta, e níveis de pressão bastante superiores (cerca de 4 vezes) à tensão de cedência dos materiais.

- Foram atingidas neste trabalho velocidades de soldadura elevadas na soldadura de chapa fina de aço galvanizado e aço carbono. Estes valores foram possíveis devido ao facto de se terem utilizado condições operatórias que eliminaram problemas típicos dos materiais e espessuras seleccionadas.

- A dimensão dos cordões obtidos é típica da soldadura em modo keyhole (razão largura/penetração entre 1 e 1,2), apresentando extensões de zona termicamente afectada bastante estreitas (menor que 0,2 mm).

- Na zona adjacente ao cordão observou-se uma camada de zinco fundida, com uma extensão que não ultrapassa os $2 \mathrm{~mm}$. Esta camada é regular ao longo de todo o cordão, mantendo a protecção à corrosão. Devido ao facto de apenas se ter volatilizado o zinco relativo à largura do cordão, a resistência à corrosão da junta soldada é semelhante à do aço galvanizado, um vez que o zinco adjacente ao cordão de soldadura garante a protecção catódica.

- O procedimento desenvolvido para a soldadura por laser de $\mathrm{CO}_{2}$ dos aços St 1203 e St $02 \mathrm{Z}$ (espessuras de $1,25 \mathrm{~mm}, 0,75 \mathrm{~mm}$ e $0,50 \mathrm{~mm}$ ), nas várias combinções de espessuras e materiais, garante uma elevada qualidade das soldaduras, como se comprova pela análise realizada segundo a norma EN ISO 13919-1, pela observação metalográfica, pelos valores de microdureza obtidos e pelos resultados do ensaio de tracção.

\section{REFERENCIAS}

(1) BAYRON J. "An update on mash seam resistance welding" Welding Journal $\mathrm{n}^{\circ} 7$ vol. 73 , ed. American Welding Society p 35-39, Julho 1994.

(2) Jaroni U., Prange W., Schneider C. "Tailored Blanks", Proceedings of the LANE'97 (Laser Assisted Net shape Engineering), ed. Meisenbach-Verlag Bamberg, p 61-67, Erlangen, Setembro 1997.

(3) ARATA Y. "The role of assist gas in $\mathrm{CO} 2$ laser welding", Plasma, Electron and Laser Beam Technology, ed. America Society for Metals, p 498-505, Ohio, 1986.

(4) Peças P., Henrique M., Miranda R.M., Quintino L. "Laser welding of low-thickness zinc-coated and uncoated carbon steel sheets", Optica and Quantum Electronics n ${ }^{\circ}$ 27, ed. Chapman \& Hall, p 1193-1201, 1995.

(5) CARTER S. "Developing performance validation and acceptance procedures for commercially built tailored blank laser welding systems", Proceeding of IBEC '96 Materials \& Body Testing, ed. Automotive Technology Group, Inc., p 121-131, Detroit, Outubro 1996.

(6) Peças P., Henrique M., Miranda R.M., Quintino L. "Laser welding of low-thickness zinc-coated and uncoated carbon steel sheets", Optica and Quantum Electronics $n^{\circ}$ 27, ed. Chapman \& Hall, p 1193-1201, 1995.

(7) Peças P., Henrique M., Miranda R.M., Quintino L. "Laser welding of thin sheets" Proceedings of International Institute of Welding Assembly, Pequim, Setembro 1994.

(8) Peças P., Henrique M., Miranda R.M., Boldura L.M. "Laser welding carbon and zinc coated steel", Proceedings of the LANE'94 (Laser Assisted Net shape Engineering), ed. Meisenbach-Verlag Bamberg, p 177-183, Erlangen, Setembro 1994. 